\title{
From a Quality Management System (QMS) to a Lean Quality Management System (LQMS)
}

\author{
Pascal Bacoup ${ }^{1}$, Cedric Michel ${ }^{1}$, Georges Habchi² ${ }^{2}$ Magali Pralus ${ }^{2}$ \\ ${ }^{1}$ Univ. Cergy Pontoise, IUT QLIO, 95011 Cergy-Pontoise, France \\ Pascal.bacoup@u-cergy.fr, Cedric.michel@u-cergy.fr \\ ${ }^{2}$ Univ. Savoie Mont Blanc, SYMME, F-74000 Annecy, France \\ Georges.Habchi@univ-smb.fr, Magali.Pralus@univ-smb.fr
}

\begin{abstract}
Purpose - This article deals with the subject of "Lean Normalization". A comprehensive methodology is proposed which combines the benefits of both ISO standards and Lean Management. The application of this methodology leads manufacturing or service companies to certification without creating more documentation. It guarantees agility and flexibility in the day-to-day management of the company, and induces lower costs and reduced times. This methodology provides a new way of tackling the implementation of ISO Standards in a company.

Design/methodology/approach - This methodology is based on the synergistic combination of both ISO Standards (Quality Management System) and the key concepts of Lean Management.

After a short presentation of ISO Standards and Lean Management, the possibility of implementing a synergy between these two different approaches will be discussed. At this point ISO 9001 standard will be focused on. The proposed methodology will be introduced step-by-step. Each step of the model will be formalized using the SADT graphic representation tool. Moreover, each step is associated with a key concept of Lean Management. In order to illustrate the proposed method, an example of implementation will also be presented.

Findings - To show the feasibility of this methodology, this article finishes with a summary of the results achieved in a company and draws some interesting conclusions. Companies have the possibility of achieving certification in combination with a Lean Quality Management System: a one-page Quality Manual, only ten records, no major nonconformities and no customer complaints over a two-year period.

Research limitations/implications - The methodology may have to be adapted to better suit the needs of companies seeking to implement the latest version of the ISO 9001 standard.

Practical implications - This paper presents the deployment of ISO 9001 standard whilst simultaneously respecting key Lean Management concepts. The practical results for enterprises are the implementation of a Lean Quality Management System leading to a certification.

Originality/value - Due to its simplicity and the relevance of its steps, the proposed methodology can be applied to companies with a guaranteed success of certification.

Keywords ISO, Standards, Lean Management, Performance, Continuous Improvement, Perfect Quality.

Paper type Research paper.
\end{abstract}

\section{Introduction}

Lean Management originated in the firm Toyota in the middle of the $20^{\text {th }}$ century and was then conceptualized at the end of the 20th century. Its main objective is to focus on the process of waste elimination in order to cut out steps that do not create value or, in other words, to reduce anything 
a final customer would not agree to pay for. The Lean Management philosophy enables the continuous improvement of both the quality and robustness of the product/process pair. One important point of these projects is that the implementation time is always short (it does not last more than a few months) and, in any case, there is usually a financial objective associated with it (Hofer et al., 2012; Ahmad et al., 2012). Lean tools (e.g. 5S, Gemba walk, Kaizen, etc) are often simple to use without having the need for complex statistical tools (6 Sigma Tools), but, despite this, they generally do use statistical methods. This is why Lean tools are playing an increasingly important role in the field of statistical research (Nasab et al., 2012; Fagerlind Stahl et al., 2015).

The implementation of ISO standards occurs simultaneously with a comparable focus on continuous improvement. Nevertheless, unlike Lean philosophy, it is based on the description and optimization of the organization in order to define the minimum requirements that influence product quality and customer satisfaction directly (Naveh and Marcus, 2005; Terlaak and King, 2006; Shah and Ward, 2007). Furthermore, it is crucial to notice that the time scales are longer when aiming to achieve the relevant certification (experience shows it takes one to three years depending on the resources in the company and the complexity of the organization). It is possible to obtain certification within an organization when a Quality Management System (QMS) is operational, but the return on investment is not necessarily taken into consideration. The following few references deal with the latter topic (Withers and Ebrahimpour, 2000; Terziovski et al., 2003; Sharma, 2005; Naveh and Marcus, 2005; Terlaak and King, 2006; McGuire and Dilts, 2008; Tamayo-Torres et al., 2014).

\section{Lean Management}

Numerous publications deal with this approach, but there is no universally accepted definition of Lean Management. A bibliographical study by Holweg (2007), traces the history of major published references in this field before 2007. In addition to this literature review, Lyonnet proposed an exhaustive study of the main concepts of Lean Management (Lyonnet et al., 2010). In her $\mathrm{PhD}$ thesis, she analyzed 27 referring authors. Her personal analysis led to the conclusion that six concepts form the foundations of the Lean approach:

- Elimination of waste: Waste is defined as an action or a non-value-creating situation for the customer (Womack and Jones, 1996).

- Just-In-Time: Elimination of the unnecessary work-in-process to ensure a continuous flow of products (Ohno, 1988).

- Continuous Improvement: "Continuous improvement" is also known as Kaizen and is based on "the empowerment of each for the cult of best" (Imai, 1997).

- Perfect Quality: Optimization, perfection and principle of "best quality" (James-Moore and Gibbons, 1997; Åhlström, 1998; Liker, 2004; Womack and Jones, 1996).

- Visual Management: Use of visual tools and indicators to guarantee that the activities flow correctly (Liker, 2004).

- Human Resources Management: Associated responsibility by participating in the team to be able to make the company win (Ohno, 1988).

To complete this analysis and check the relevance of these concepts, this bibliography will be expanded to include 34 new articles that have been identified since 2010 as shown in Table 1. 


\begin{tabular}{|l|c|l|c|}
\hline Reference & Number & Reference & Number \\
\hline Ahmad et al., 2012 & 1 & Johnstone et al., 2011 & 18 \\
Atmaca and Girenes, 2013 & 2 & Krogstie and Martinsen, 2013 & 19 \\
Cuatrecasas-Arbos et al., 2011 & 3 & Metternich et al., 2013 & 20 \\
Bakri et al., 2012 & 4 & Al-Tahat and Jalham, 2015 & 21 \\
Behrouzi and Wong., 2011 & 5 & Nasab et al., 2012 & 22 \\
Bortolotti et al., 2015 & 6 & Netland et al., 2015 & 23 \\
Chavez et al., 2015 & 7 & Pamfilie et al., 2012 & 24 \\
Deif, 2012 & 8 & Peter and Lanza, 2011 & 25 \\
Dombrowski et al., 2012 & 9 & Purvis et al., 2014 & 26 \\
Dominici and Palumbo, 2012 & 10 & Rahani and al-Ashraf, 2012 & 27 \\
Eroglu and Hofer, 2011 & 11 & Ravet, 2011 & 28 \\
Fullerton et al., 2013 & 12 & Schwarz et al., 2011 & 29 \\
Gligor et al., 2015 & 13 & Fagerlind Stahl et al., 2015 & 30 \\
Gnogni et al., 2013 & 14 & Turner and Lane, 2013 & 31 \\
Hofer et al., 2012 & 15 & Tyagi et al., 2015 & 32 \\
Holtskog, 2013 & 16 & Wasim et al., 2013 & 33 \\
Jabbour et al., 2013 & 17 & Yang et al., 2011 & 34 \\
\hline
\end{tabular}

Table 1. Numbered references considered in Table 3

Based on the bibliographic results and this complementary analysis, Figure 1 shows the order of importance of the Lean concepts as a function of the number of citations:

- 128 for Just-In-Time,

- 114 for Perfect Quality,

- 91 for Team Management,

- 54 for Elimination of Waste,

- 46 for Continuous Improvement and,

- 28 for Visual Management.

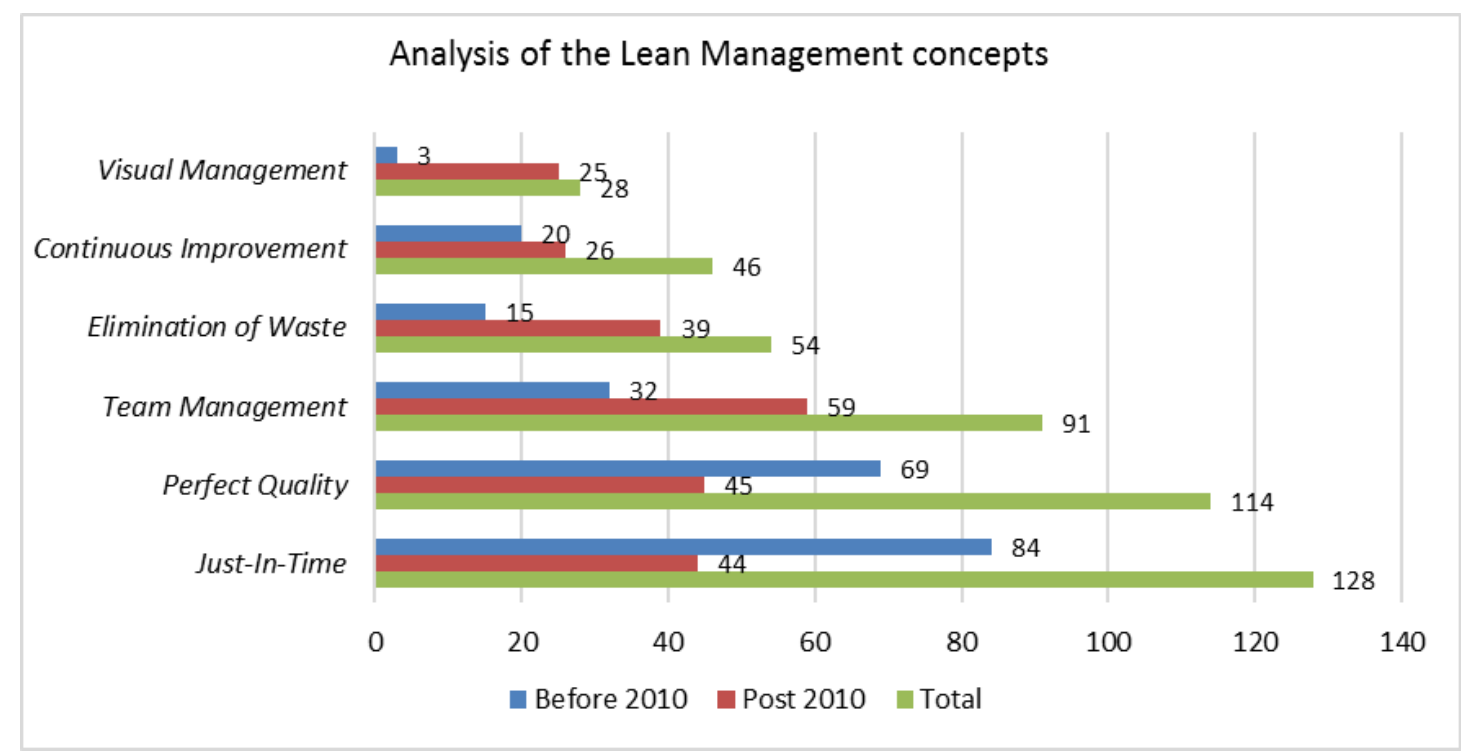

Figure 1. Analysis of the Lean Management concepts 
If the total value of citations is almost the same for the analysis made before 2010, (with one exception: Continuous Improvement arrives before Elimination of Waste), it is not respected if the study only considers the literature post-2010. Indeed, the difference in the importance of the concepts is not as noticeable as before 2010 in terms of number of citations. Before 2010, the number of citations of concepts varies from three to 84 while after 2010 it is between 25 and 59 . The examination of the importance of the concepts individually shows that, the ranking of the concept of Team Management is first with 59 citations, while that of the two concepts of Just-InTime and Perfect Quality is virtually the same (44 and 45 citations). The importance of Visual Management emerges strongly (from 3 citations before 2010 to 25 citations after 2010) and its level of importance is the same as the concept of Continuous Improvement (26 citations).

Hence, it can be hypothesized that the successive economic crises (since the subprime mortgage crisis in 2008) have certainly had an impact on the orientations of the concepts of Lean Management.

Table 2 summarizes the main basic principles in relation to the six concepts of lean management highlighted previously.

\begin{tabular}{|l|l|}
\hline Lean concepts & Basic principles \\
\hline Just-In-Time & Pulled flows, pushed flows, just-in-time, Kanban.... \\
\hline Perfect Quality & $\begin{array}{l}\text { Standard processes, quality management, capability process, detection } \\
\text { and resolution of dysfunctions... }\end{array}$ \\
\hline Team Management & $\begin{array}{l}\text { Human resources management, multifunction of the teams, teamwork, } \\
\text { teamwork and participation... }\end{array}$ \\
\hline Elimination of Waste & Production analysis, value, value streaming... \\
\hline Continuous Improvement & Kaizen, continuous improvement \\
\hline Visual Management & Visual management \\
\hline
\end{tabular}

Table 2. Basic principles related to Lean concepts

Therefore, Table 3 recapitulates the 34 main references, considering the six concepts as the first classification key, then the principles that emerge from them as the second key. To simplify the presentation of this table, the numbers associated with references are used.

In conclusion, the six concepts of Lean Management analyzed in this study are considered. This analysis clearly demonstrates that all the concepts of Lean Management continue to be consistent with the results of the bibliographic research (Figure 1, Table 3). 


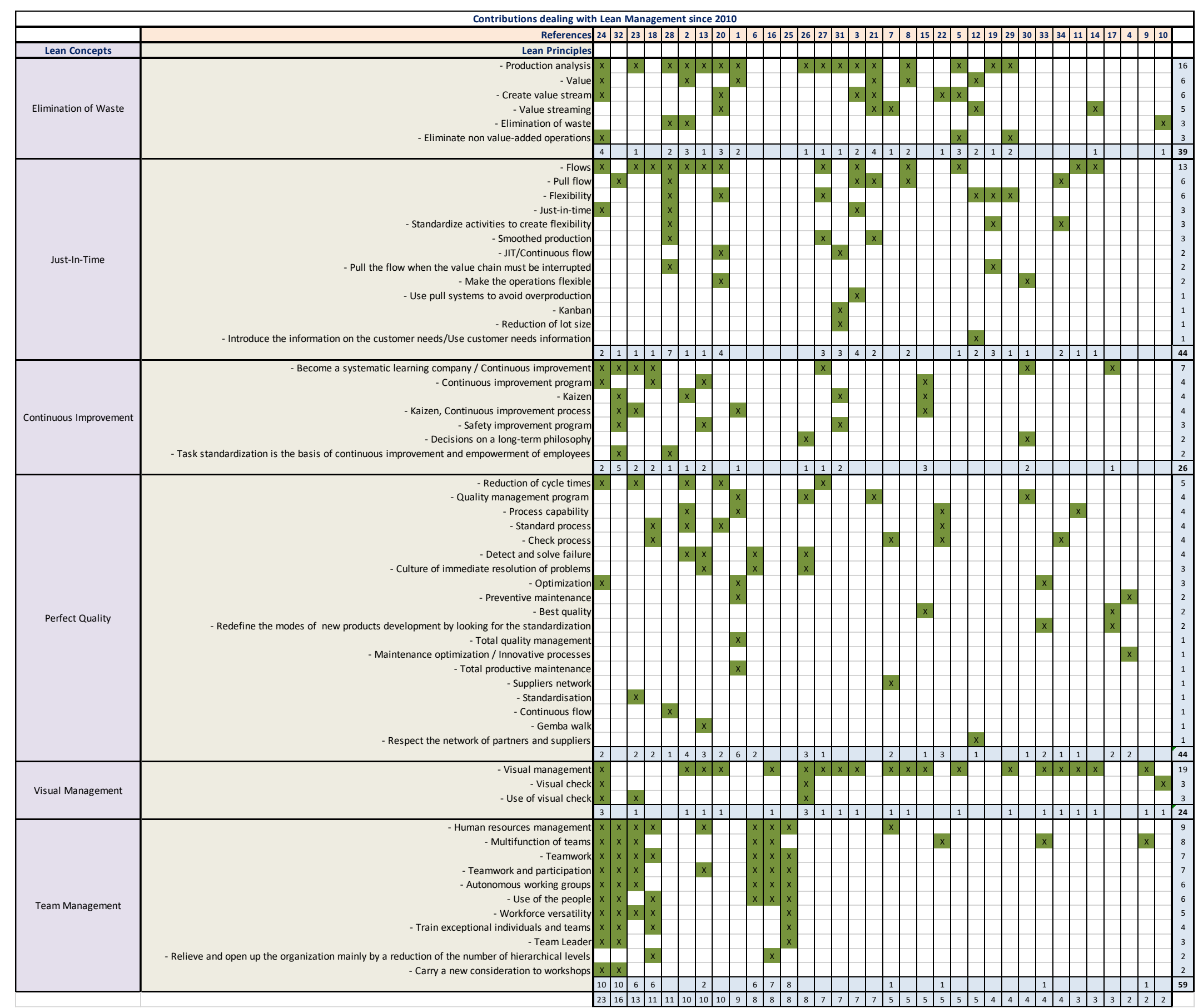

Table 3. Main contributions concerning Lean Management, since 2010. 


\section{ISO 9001}

ISO or International Organization for Standardization is an organization that allows companies and businesses to be certified through a collection of standards. This certification applies to the fields of Quality and/or Environment (standards in the 9000 and 14000 series) and allows the enhancement of continuous improvement in the organizational process. This certification is subject to an audit by certification bodies. In addition, it allows the organizations to communicate positively with the relevant parties (customers, suppliers, operators, etc.).

In comparison, for Lean Management, fewer contributions deal with the implementation of ISO standards in a firm. Most of these contributions describe applications in a country or in an industrial field (Stålhane, 2006; Turk, 2006; Din et al., 2011; Priede, 2012). For example, the article proposed by Yuan-Han and Anand (2014), considers the application of ISO standards in a hospital department.

This paper deals with ISO 9001 standard, even if propositions are applicable with ISO standards in general.

One breaking point with ISO 9001 models is that the first version of the standards required a lot of documentation and, from that moment on, quality was understood to be a huge documentation system burdened with a high level of bureaucracy and essentially non-operational for workers. The post ISO 9001: 2000 standards were more process-oriented than the earlier versions and required fewer documents. However, for the firms that followed the older version, it was very difficult to lay out all the documentation work and optimize it (Liker, 2004).

Even if it is a common misconception at many levels for old school managers, the documentation nightmare myth of ISO 9001 remains present in some sectors. Many companies that are ISO 9001 certified have actually over-documented and created cumbersome Quality Documentation Systems that provide little value and for which they have no controls in place to avoid them becoming even bigger (Micklewright, 2010).

The purpose of this research is to contribute to a better understanding of the ISO 9001 requirements, which is the key to an effective QMS as put forward by Wilson (1998) who advocates keeping the documentation simple and easy to use.

\section{Lean Management and ISO 9001}

Examining the similarities and differences between Lean Management and ISO 9001 highlights a close relationship, which raises a key question about their potential linkage: if both Quality Management System and Lean Management are complementary and mutually reinforcing, why are they not used as an integrated combination? To tackle this issue and fill an existing gap in the literature regarding their association, Micklewright, founder of "Quality Quest Inc", wrote a reference book entitled "Lean ISO 9001" published in 2010 (Micklewright, 2010) dealing with the practice of applying Lean management into ISO 9001-based Quality Management System (QMS). He claims there is an irony in the fact that QMS and Lean are both intended to improve the production processes of the firm whereas, in reality, they are two parallel systems and governance structures driven by two different departments, resulting in wasted resources because they are not properly aligned.

According to Micklewright, the waste involved in having multiple systems serving the same purpose can be enormous, and this lack of organizational synergy could be the source of the rupture between the two approaches. Actually, he considers that Lean and Quality Managers in top management should work together to understand and eliminate the redundancies in the two systems. Deploying this strategic plan, which organizes the company into value streams, is the 
only efficient way to merge Lean practices into a QMS thus making both systems more effective and in accordance with the spirit of both Lean and ISO 9001. However, he does not describe in detail which tools or methods should be applied. He only used the $5 \mathrm{~S}$ method to reduce the documentary system in a QMS. Another key point is the fact that Micklewright's approach deals with an existing QMS whereas it would be more effective to directly set up a Lean QMS before starting the certification process. When operating independently, Lean processes can indeed create a fragmented business approach that damages the company's core quality process. It is certainly better to use the six fundamental concepts of Lean Management analyzed in the Lean Management section when an organization begins to implement ISO, than try to create a Lean Quality Management System (LQMS) with an existing QMS. Actually, it is smarter and faster to build a management system from scratch rather than to patch up a corrupted existing system under the umbrella of Lean Management. Otherwise, the Lean System can get out of hand and become an entity in its own right like a stand-alone satellite system. Furthermore, Micklewright identifies documentary entropy in his analysis, which rarely generates value. This entropy is often presented in publications as an obstacle to the implementation of ISO 9001 (Liker, 2004; Ballé and Beauvallet, 2013).

In addition, there has been a recent attempt to define a guideline integrating ISO 9001 and Lean thinking (FDX 50-819, 2011). FDX 50-819, is a French document of about forty pages, which seeks to cross-reference the ISO 9001 requirements with Lean principles and tools such as value stream mapping, Jidoka, $5 \mathrm{~S}$, etc. The primary purpose of this document is to highlight the most appropriate tools in Lean for a complimentary interaction with each clause of the ISO 9001 standard. Therefore, quality managers and consultants can use this guideline for an application of Lean thinking within a QMS in order to investigate the impact on documentation. Objectively, these recommendations do not propose a practical documentary model, compatible with ISO 9001. It is more about the synchronization of Lean tools with ISO clauses, or requirements. This approach follows Chiarini's recommendations (Chiarini, 2011) because the author proposes operational tools in order to synchronize the ISO 9001 clauses with the operational tools stemming from Lean thinking.

Blecken et al. (2011) proposed also to put the Lean Management and the ISO 9001 standard in synergy. The authors propose a "toolbox" that synchronizes Lean tools, ISO clauses and a company's processes. Unfortunately, it seems that the synchronization is conducted in a very macroscopic way and does not directly affect the documentary structure.

As a result, after this bibliographic study of existing knowledge about valuable synergies between ISO 9000 and Lean, it appears that the above-mentioned methods propose a simplification of the already existing management system. Actually, their common features include a comparative perspective of the normative clauses with an immediate application of Lean tools.

This way of working may be ideal for companies only concerned with short-term benefits. In this case, such firms are looking for ISO 9001 certification just to satisfy specific customers who state they will only do business with partners that are certified as ISO 9001 compliant. In other words, these organizations only seek to obtain a piece of paper (the ISO certificate) by any means because they are only interested in their immediate gains and do not embrace the concept of customer satisfaction as the ultimate goal of a QMS. Focusing only on the short-term gain, they then specifically apply the principles of Lean as a layered method without any deep and sustainable improvement.

It can be assumed that the main issue with this sequential approach, which is extremely expensive, is that it ignores the long-term benefits. It is worth noticing that works have not been identified which suggest directly applying the Lean concepts to the analysis of a standard. 
For this reason, the "Lean Normalization" methodology, which naturally leads to the so-called Lean Quality Management System (LQMS) is being proposed. It is worth noticing that his topic has never been dealt with in the full range of publications analyzed.

\section{Lean Normalization}

In order to improve the implementation of an ISO standard, in synergy with Lean thinking, the application of the "Lean Normalization" methodology is proposed in this research paper. This involves a modelling phase and an implementation phase in the section assigned to the application. This research was initiated over 4 years as part of a $\mathrm{PhD}$ thesis and some communications have already been presented (Bacoup et al., 2014; Bacoup et al., 2015a; Bacoup et al., 2015b).

This modelling phase includes six steps adapted from the analyzed Lean Management concepts. It is about a continuous and parallel process and not a sequential one, especially for the last three steps. "Lean Normalization" will be applied to the ISO 9001 standard.

The proposed methodology, which integrates Lean thinking, enables each firm to develop, firstly, the minimum amount of documentation needed in order to demonstrate the effective planning, and secondly setup and control its processes and their continuous improvement (design of the continuous improvement process) so that the QMS is as efficient as possible. This subject will be dealt with by applying the six key Lean concepts identified in section 2 . These six concepts correspond to the six steps of the "Lean Normalization" process. The "Lean Normalization" leads to an integrated and agile QMS called Lean QMS:

- Elimination of waste: A01 - Documentary Muda. The purpose of this step is to identify the right level of documentation and the exact number of documents required by the ISO 9001 standard (One quality Manual, three procedures and twenty-three records for the 2015 version).

- Just-In-Time: A02 - Right Documents. The aim of this step is to match the requirements of the ISO 9001 standard with the existing documentation issued from the organization of the firm.

- Continuous improvement: A03 - Design of the Continuous Improvement Process. It describes the management of processes involving the executive committee and scorecards to control the improvement process.

- Perfect Quality: A04 - Due Quality. The Due Quality represents the opportunity to apply all the basic principles related to this concept to improve the quality of the organization and product/service.

- Visual Management: A05 - Visual Communication. This step allows the communication of the LQMS to all the employees in the firm using a visual scorecard.

- Human Resources Management: A06 - LQMS Animation.

Figure 2 provides a top-down hierarchical model with three levels of this methodology. The upper level (level 1) corresponds to the overall process of "Lean Normalization". Level two details the six Lean concepts codified A01 to A06. Then on level 3 each concept is broken down to illustrate its model consisting of activities, inputs, outputs, constraints and support means. 


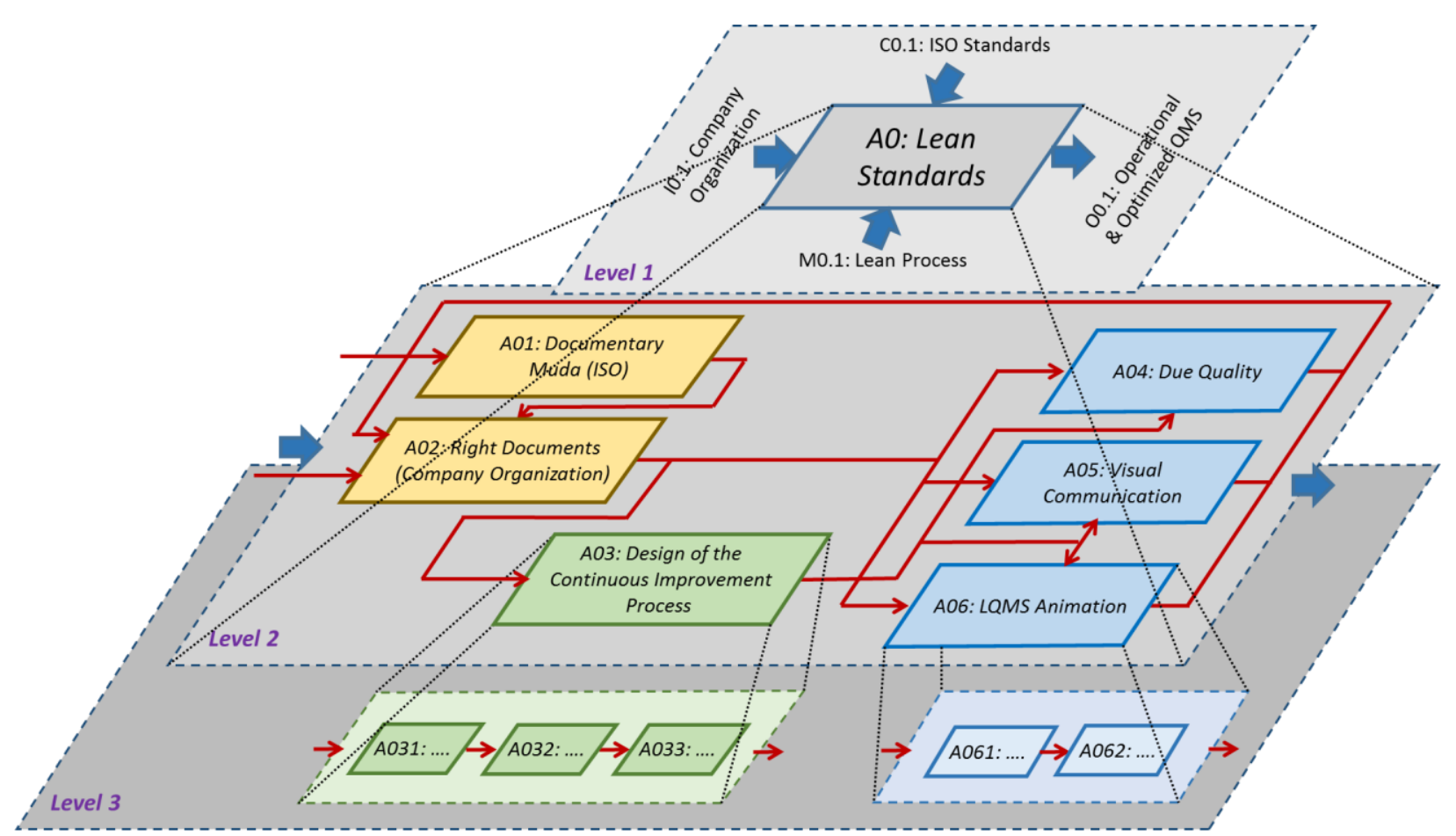

Figure 2. The overall "Lean Normalization" hierarchical model

To build the six-step model, the SADT (Structured Analysis and Design Technique) formalism is used (Marca and McGowan, 1988; Waldner, 1992; IDEF0, 1993). SADT is a top-down, structured approach originally allowing the description of information systems development. The graphics formalism permits the modeling of task decomposition and interaction between processes. SADT is also used to model production or service processes, or to structure, for example, risk analysis (Piatyszek and Karagiannis, 2012).

Five features represent each task, activity or process described (Figure 3):

- Activities or sub-activities (called Axxx) that make up the step.

- Input elements (called Ixxx.x) requisite to perform the activity.

- Constraints (called Cxxx.x) identified for the activity. A constraint controls the achievement of the activity.

- Means or resources (called Mxxx.x) necessary for the achievement of the activity.

- Output elements (called Oxxx.x) generated by the activity. An output element can be used as an input, constraint or means for other activities.

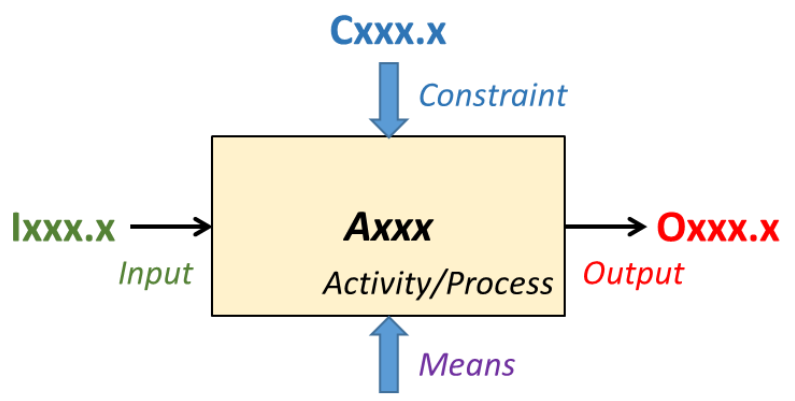

Mxxx.x

Figure 3. SADT Formalism

Figure 4 clarifies the numbering system used for each feature of the SADT formalism. 
Activity code

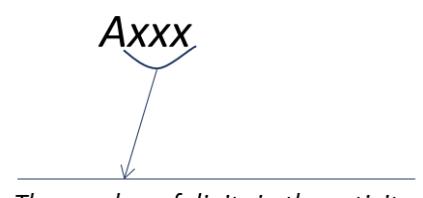

The number of digits in the activity code specifies its hierarchical level (Example: A012 $\rightarrow$ Activity number 012 in level 3)
Code of an element connected to activity Axxx

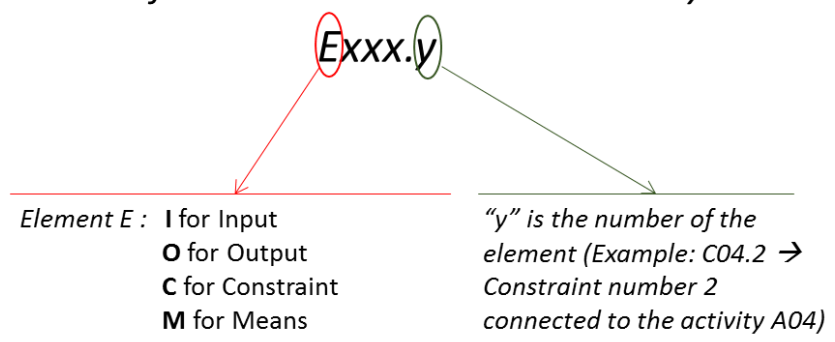

Figure 4. SADT numbering system

In this section, a six-step model is detailed and built at level three of the hierarchical structure, for all six concepts as well as practical examples performed in a company or organization. This model is generic enough to be applied to other ISO standards.

\section{Step 1: The Documentary Muda}

Based on the SADT formalism, Figure 5 shows the model for this step, which summarizes the main activities, inputs, outputs, targets and support tools.

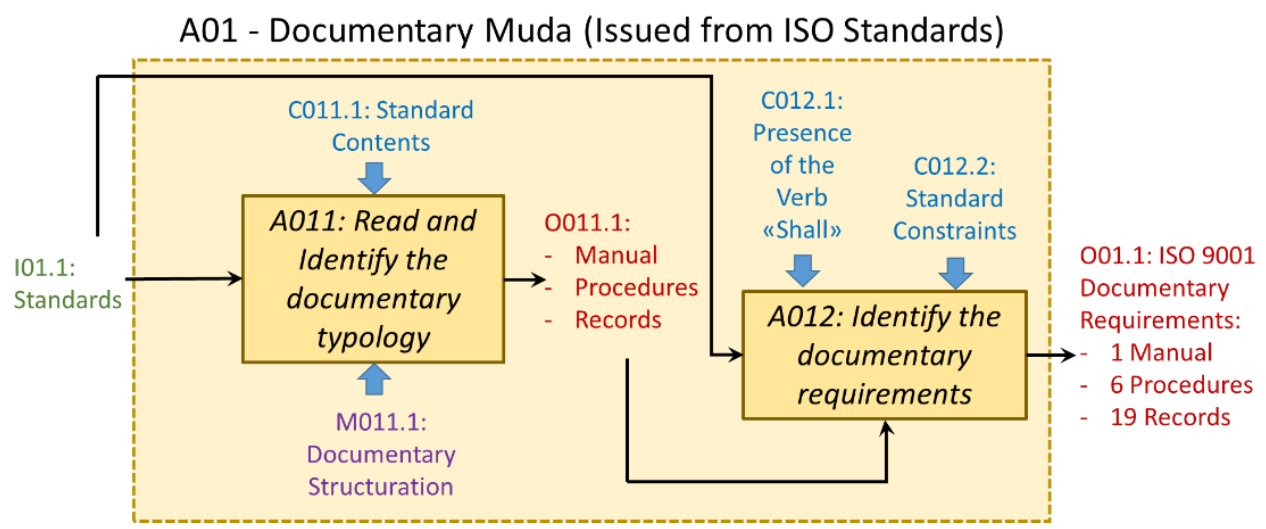

Figure 5. The "Documentary Muda"

The model consists of two main activities, which are the reading and identification of the documentary typology (A011) and the identification of document requirements (A012).

Definition: Analysis of the documents required by a standard (including structuration, typology and number).

Inputs: Only use the standard and nothing else.

Outputs: Identify the exact number and the typology of the necessary documents.

Target: "Documentary Muda" involves the analysis of the precise nature of the documentary requirements necessary in the standard. In this example with ISO 9001, there is one quality manual, six procedures, and 19 records.

Tools: An Excel file is used to collect the number and the typology of the compulsory documents and analyze the requirements of the standard.

If the model is directly applied to the ISO standard, it can be produced as shown in Figure 6: A Quality Manual, 6 procedures (Documentation Management, Record Management, Audit Management, Non-Conformity Management, Corrective action, and preventive action) and 19 
records. The 6 procedures can be compiled into three procedures such as: management of documentation and records, management of audits and management of continuous improvement (including non-conformities, corrective and preventive actions). For the nineteen records, the following documents were identified: management review, human resources, process record, contract review, five records for the conception management, supplier evaluation, specific processes, traceability, customer privacy, calibration records, audit records, process survey, nonconformity, corrective action, and preventive action. Some records can be compiled and not included in the certification such as conception management, because the organization does not deal with a specific product/service. At the end of this step, twelve records are obtained which are necessary for the certification.

\section{Quality Manual (Doc-QM)}
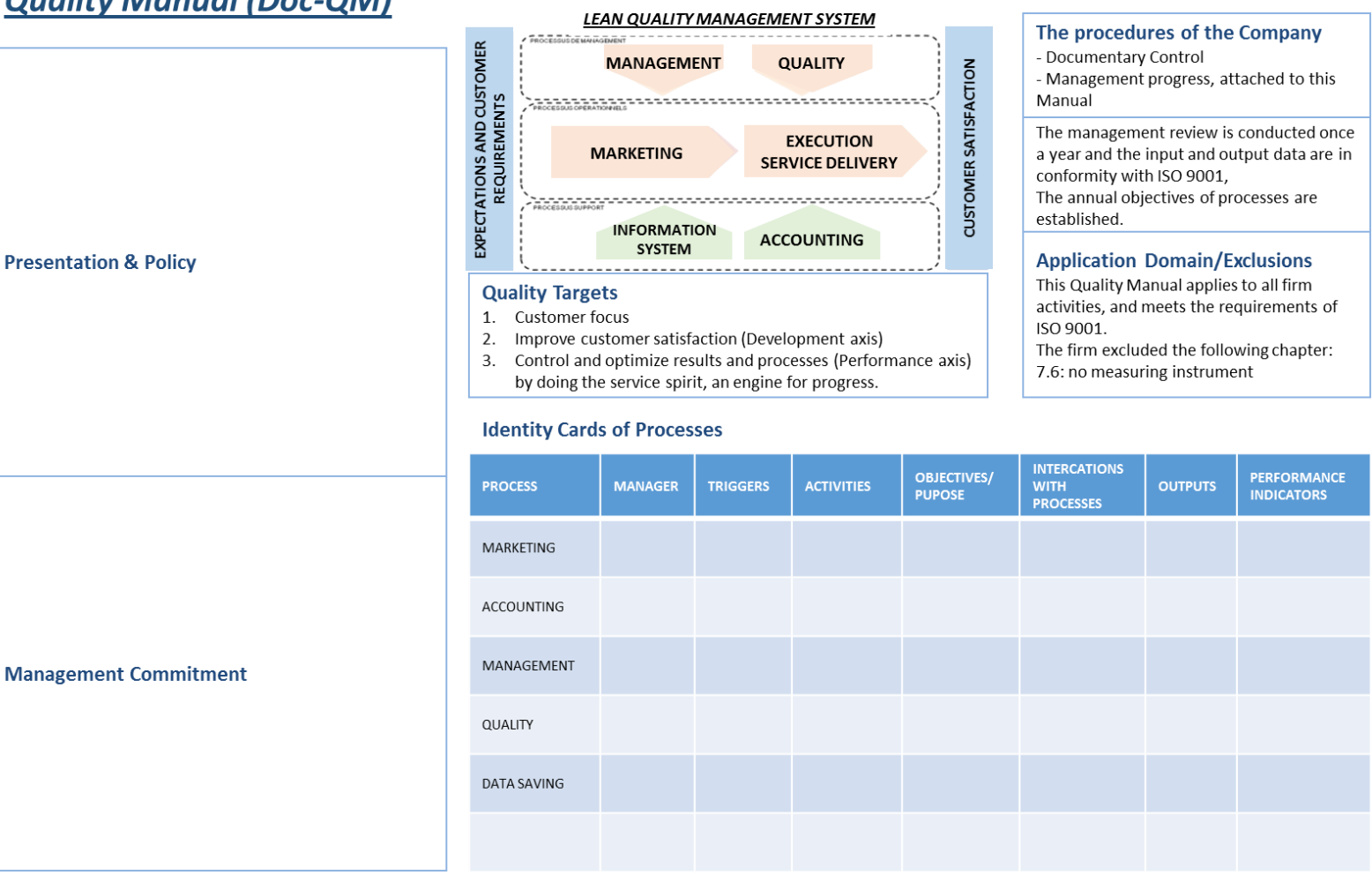

Figure 6. A quality manual in a poster format

\section{Step 2: The Right Documents}

The model for this step is shown in Figure 7, summarizes the main activities, inputs, outputs, targets and support tools for the Right Documents.

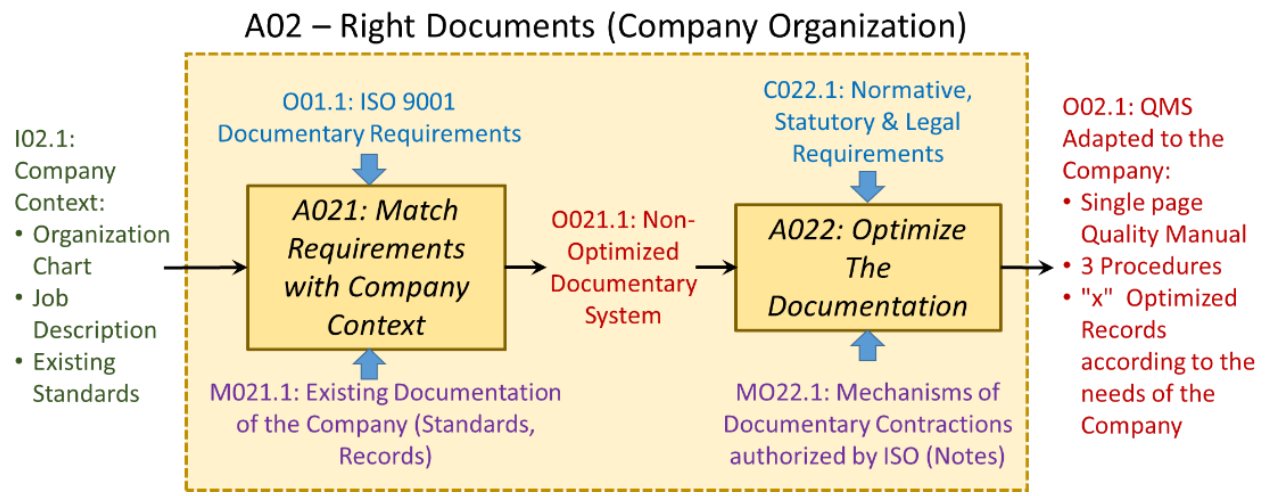

Figure 7. The "Right Documents" 
The model consists of two main activities called "A021: Match Requirements with Company context" and "A022: Optimize the Documentation".

Definition: Coherence of the normative requirements with the existing organization of the company.

Inputs: All sorts of supporting documents inherent to the description of the company are used (organization chart, job descriptions, existing standards, etc.). In some cases, there is no record of the description, and it is necessary to proceed by questioning the company's employees (interviews with key employees and management).

Outputs: The Company's documentary system is in accordance with the standard and describes the company's organization.

Target: This step allows the documentary system to be designed, starting with the analysis of "mudas", the company's organization as well as its own existing documentation system. The objective for the organization wishing to be certified is to produce "just the right quantity" in terms of documentation.

Tools: The documentation of the company is matched with the documentary requirements of the standard.

This step enables to match the ISO 9001 requirements with the reality of the organization of the firm. We use, or create if necessary, the organizational charts and any process mapping documents in order to identify the company's own documents.

To do this step successfully, it is necessary to identify the processes within the firm and to match them with the corresponding ISO processes. The SIPOC card (Supplier, Inputs, Processes, Outputs, Customer), shown in Figure 8, can help with identifying the process and all appropriate data (e.g. records, notes, databases, ...) necessary to implement the QMS in the organization.

SIPOC
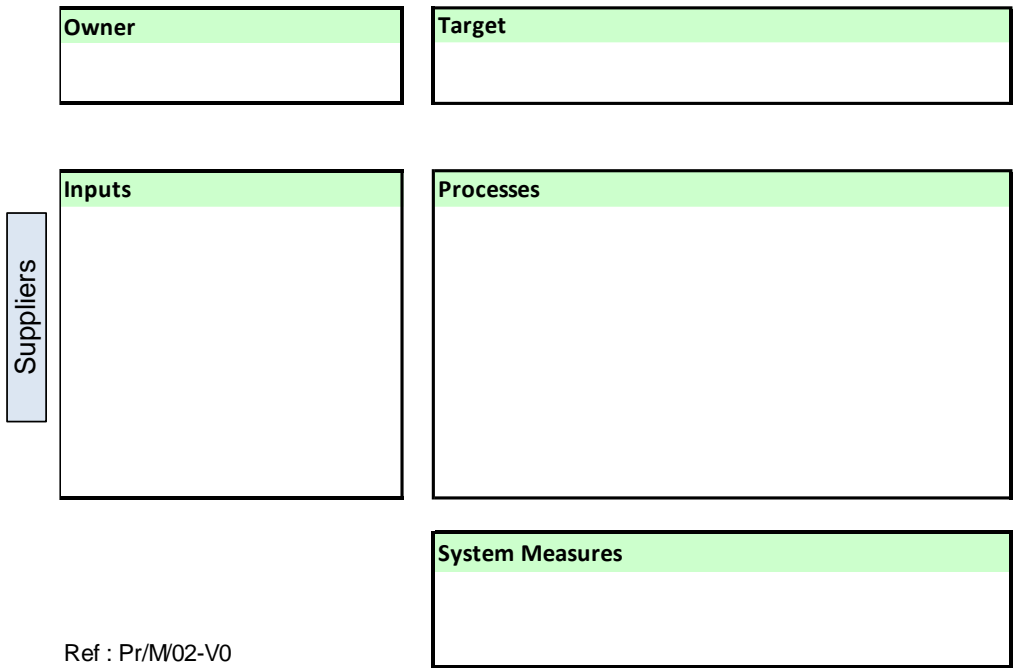

Figure 8. The SIPOC card Ref : Pr/M02-V0
Interactions betwen Processes
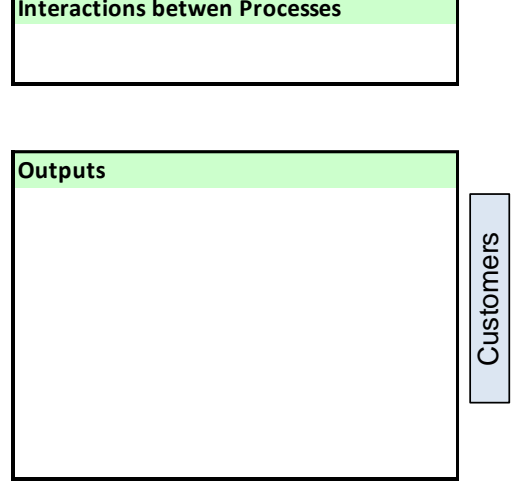

Risks Management

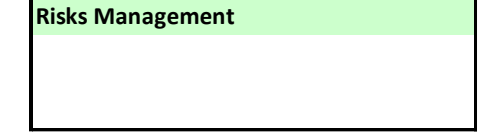

The priority is to identify the company's own inputs and outputs and match them with the analysis of the Right Documents. During this step, the whole documentary QMS is optimized and is made compatible with the standard's requirements for the documentary system. The documentary QMS 
is transformed into a Management Lean System (MLS). The next steps of the proposed model will affect the management of the operational aspects.

\section{Step 3: Design of the Continuous Improvement Process}

Figure 9 shows the model designed for this step. It summarizes the main activities, inputs, outputs, targets and support tools of continuous improvement process design.

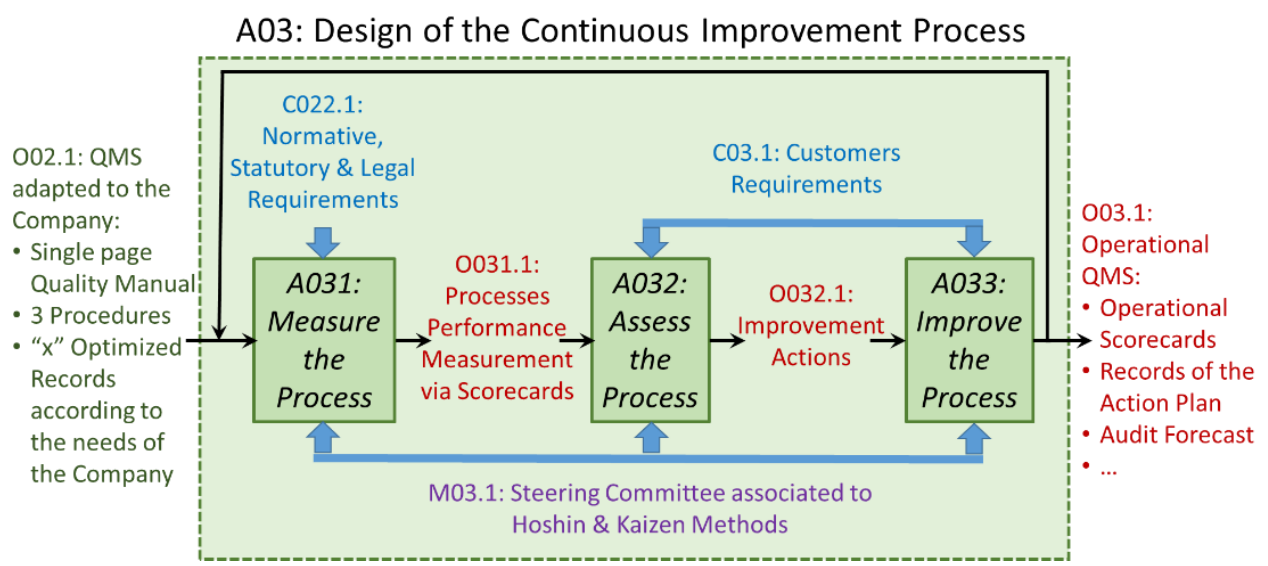

Figure 9. The "Design of the Continuous Improvement Process"

The model consists of three main activities (A031, A032 and A033) which respectively consist of, measuring the process, assessing the process and improving the process.

Definition: Implementation of optimized processes by applying the Kaizen and Hoshin methods, supervised by a Steering Committee.

Inputs: The optimized documentation of the company.

Outputs: An operational QMS with the proof (using records) of the beginning of the Continuous Improvement Process.

Target: "The continuous improvement" of the processes needs to go through an analysis of the requirements of ISO 9001 by performing a mapping of all processes. Actually, it is not the company, which identifies its own processes. Indeed, ISO 9001 standard proposes, in its latest version, ten processes.

A steering committee is formed to improve the whole process-based organization by applying the Hoshin and Kaizen methods.

Tools: Supplier Inputs Process Outputs Customer (SIPOC), Continuous improvement tools allowing the steering committee to decide on relevant actions, scorecards.

To improve this step, it is important to raise the executive committee's awareness of the importance of process improvement using scorecards and process committees. In ISO standards (9001, 14001 and upcoming 45001), this item is called HLS, which stands for: High Level System (a unified structure, which enhances the compatibility of the different standards to smooth their integration into a unique management system). All the processes need a target, which in turn, needs to be reviewed at regular intervals (every one to six months). Otherwise, it may lead to distortions of the objective.

The role of a process committee is to check the pace of the process with its manager at a predefined frequency. It enables the organization to avoid drifting from the process target. In case of 
poor results, the process committee can decide to introduce an action plan with a root cause analysis to match the process outputs with the target.

An organizational audit is possible during this period, because it enables some non-conformities with the ISO requirements to be avoided. It is important to notice that for firms that apply "Lean Normalization", the classical organizational audit does not permit to improve the organization. For this reason, a new audit model called the "organizational stress test" was proposed in a previous paper (Bacoup et al., 2015b): a five-step tool, which simulates hypothetical scenarios in a given company to check how its QMS reacts under unfavorable conditions in order to maintain a certain level of effectiveness.

\section{Step 4: Due Quality}

Figure 10 shows the model designed for this step. It summarizes the main activities, inputs, outputs, targets and support tools of Due Quality.

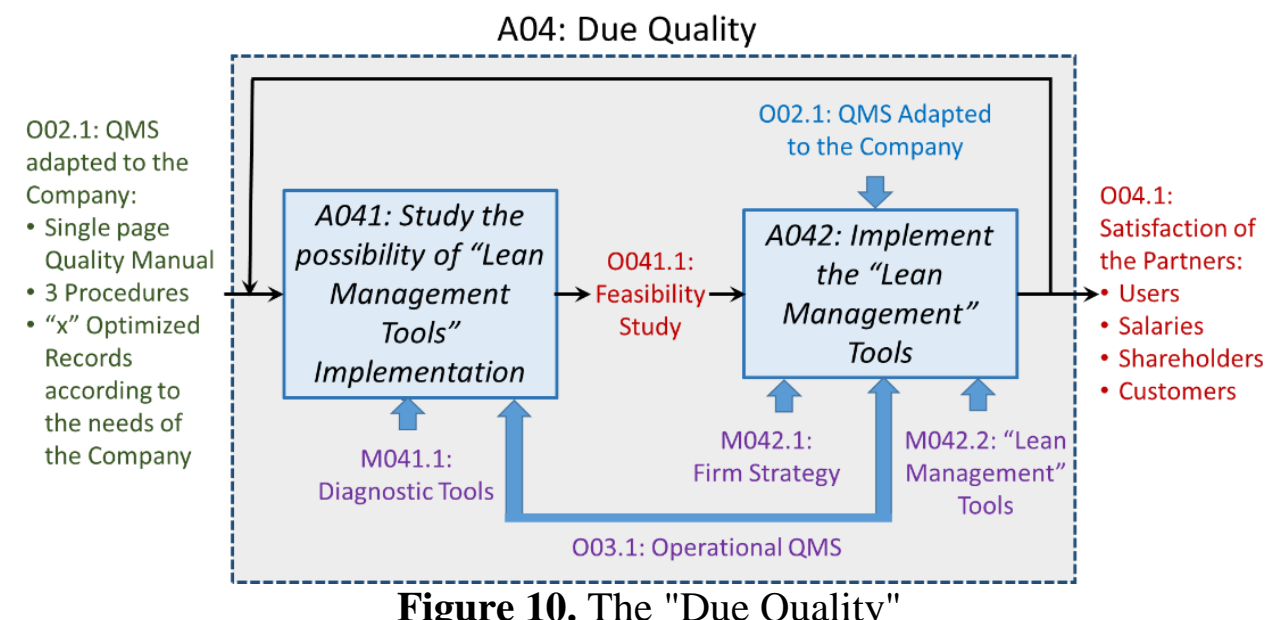

The model consists of two main activities (A041 and A042) which respectively consist of, studying the possibility of implementing Lean Management tools and the implementation of such tools.

Definition: Improvement of quality using Lean Management tools.

Inputs: The adjusted and operational QMS.

Outputs: Satisfaction of the partners (users, employees, customers, suppliers, shareholders...) regarding the quality level of the firm.

Target: The due quality, or "Jidoka of the processes" is implemented through the animation of processes by assigning clearly identified actors. Their function consists in implementing the necessary actions (organizational or operational) to reach objectives fixed by the organization's management. The actions can be modeled to establish a performance improvement plan. An important point is the fact that, at this step, all the Lean Management tools are compatible with the QMS.

Tools: It is possible to use tools such as audit (or preferably, the organizational stress test as mentioned previously), and particularly all the Lean Management tools such as 5S, 6 Sigma, etc. to improve the company's performance.

It should be noted that this step is operational and allows the use of all the Lean tools for the quality of the Process/Product tandem. Therefore, at this step, the QMS is a real MLS and begins to be fully compatible with all the Lean tools without any side effects (principally no fragmentation 
between LM and QMS, which leads to unplanned additional work and documentation) which could affect the integrity of the QMS and negatively influence the effectiveness of the QMS organization. This kind of detrimental fragmentation occurs when the new Lean initiatives are not a part of the management review process or when the eagerness to introduce Lean Management leads companies to assign exclusive priority to its implementation, which results in unintentionally abandoning their QMS. As explained previously, our fully integrated approach imposes rules to avoid this disconnection.

Some easy-to-use tools such as 5S method, CEDAC (Cause Effect Diagram with Addition of Cards), or some more complex tools such as Statistical Process Control (SPC), Design Of Experiments (Taguchi designs) and 6 Sigma can be used for the "due quality" step.

It is important to emphasize that the Lean tools used in this step positively influence the QMS. They do not introduce any additional risk (possible deletion, after a lean practice, of a record defined as essential by the ISO standard) to obtaining the required ISO certification. Indeed, the QMS is fully compatible with the Lean tools and it deals with all the requirements of the ISO 9001 standard.

\section{Step 5: The Visual Communication}

Figure 11 shows the model for this step. It summarizes the main activities, inputs, outputs, targets and support tools of Visual Communication.

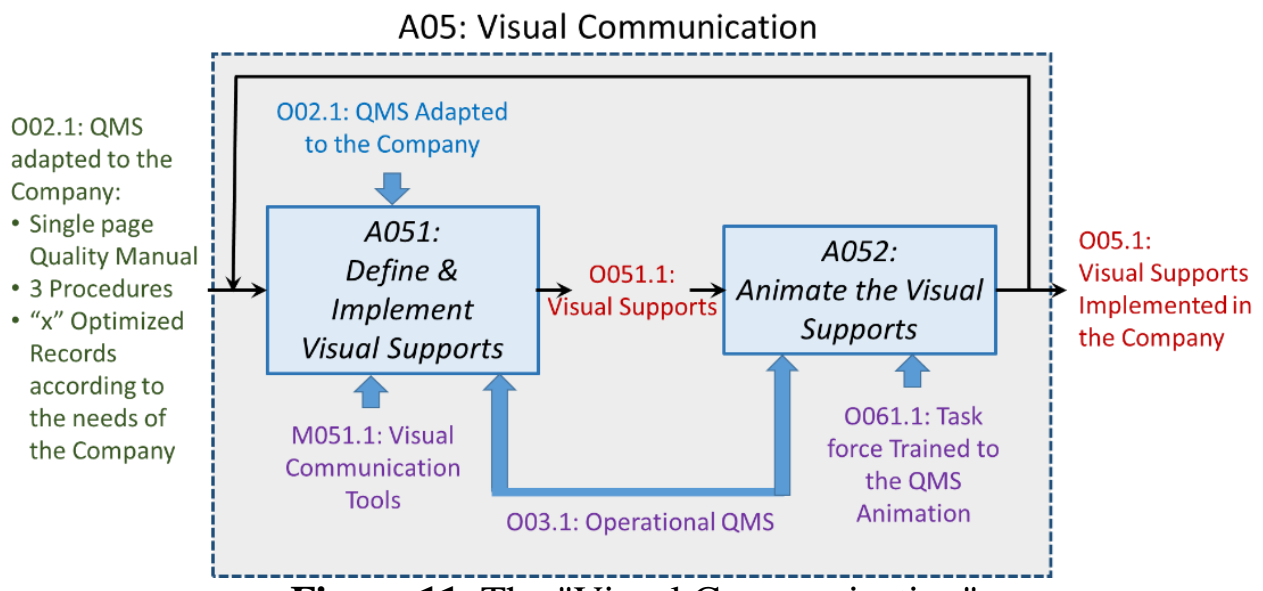

Figure 11. The "Visual Communication"

The model consists of two main activities, A051 and A052, which respectively consist of, defining and implementing a communication panel and animation of the communication panel.

Definition: Communication at all levels of the company using points of visual information.

Inputs: The QMS is adapted and operational.

Outputs: All the human resources in the company understand the QMS.

Target: The "Visual Communication" of the organizational system is interpreted using a simplified review of quality documents in the firm, where all the contributors find just what they need in order to comply with the operational requirements of the standard.

Tools: All classical tools of visual communication, such as visual report system, scorecards, etc.

Figure 12 shows a significant simplification of QMS documentation. A poster format represents the Quality manual (a), a scorecard the improvement of the process (b), and the non-conformity procedure with its corresponding zone (c). The visual QMS is adequate for the operator and 
abundant for a QMS audit. The operators do not need to learn a flow of specific information to satisfy the auditors, they only have to know where it is located and to show the ISO auditor the visual QMS in order to give a form of proof.

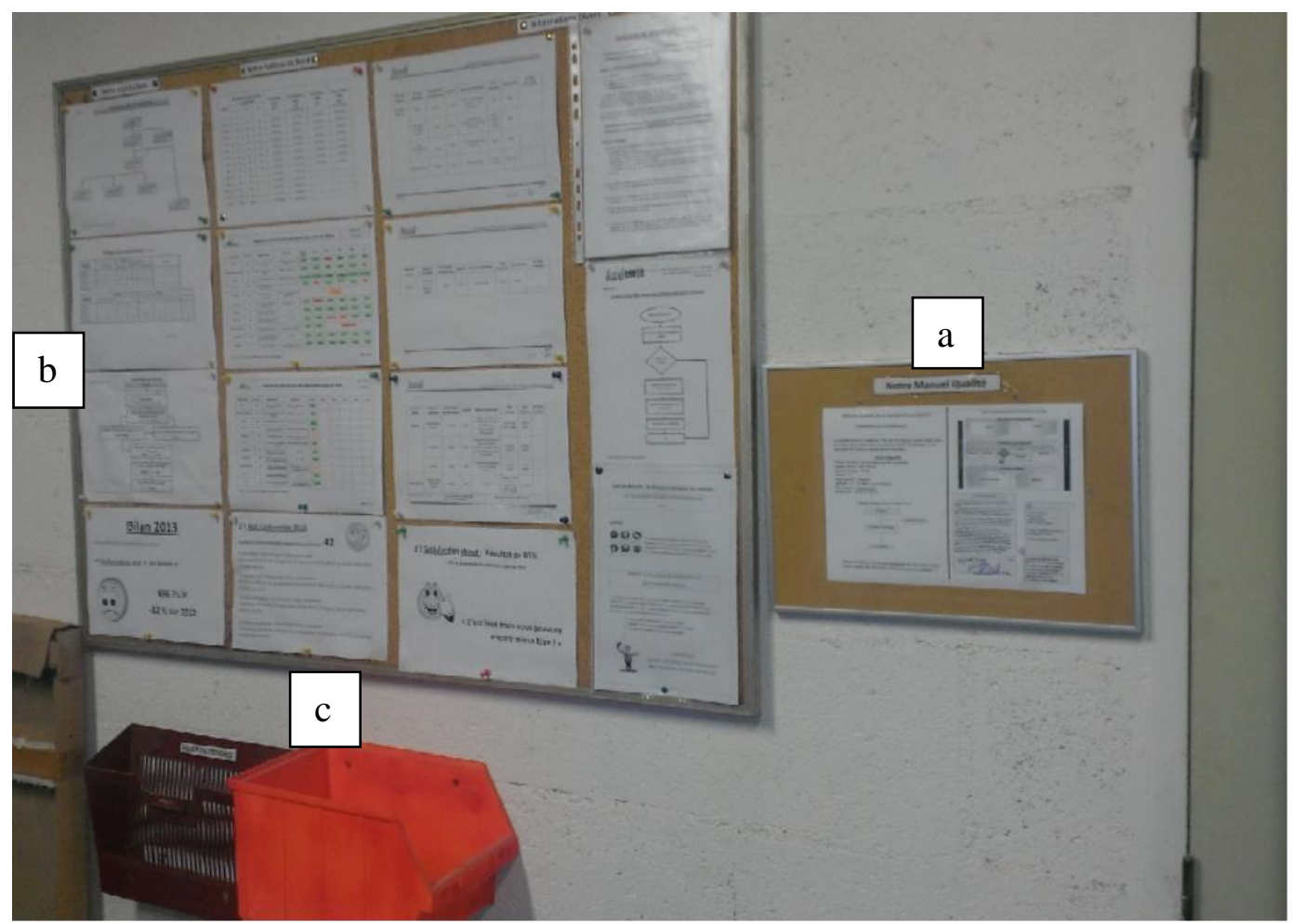

Figure 12. A visual QMS

\section{Step 6: People Management/LQMS Animation}

Figure 13 illustrates the model for this step. It summarizes the main activities, inputs, outputs, targets and support tools of People Management and LQMS Animation.

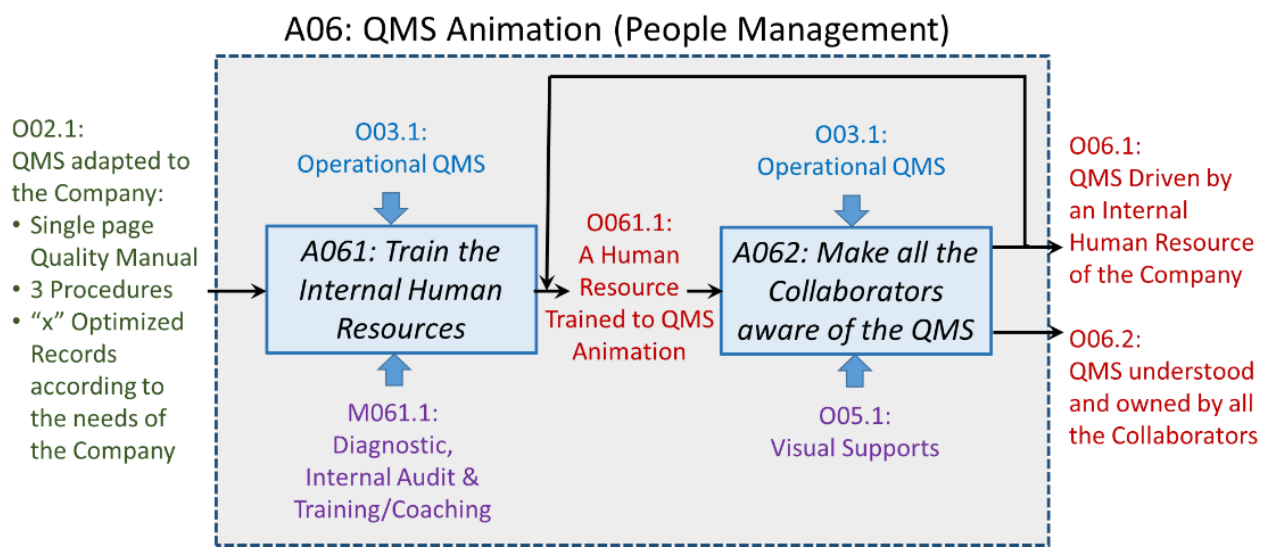

Figure 13. The "QMS Animation"

The model consists of two main activities: A061, which consists of the training of internal human resources and A062, which consists of making all the collaborators aware of the QMS.

Definition: Animation of the LQMS by a dedicated human resource. 
Inputs: The LQMS is adjusted and operational.

Outputs: A single internal human resource is able to manage the LQMS. The collaborators understand and hold the LQMS.

Target: The "LQMS Animation" ensures the versatility of the contributors, and the management of the audit maintains the different levels of the standard's requirements (managerial, organizational and operational). The system can then manage itself. It then does not require more than a documentary update of the records, and an official appointment of a contributor to hold a quality management position is not strictly needed in practice.

Tools: Use the audit (or organizational stress test), training, and coaching.

One important issue is the training of the QMS manager, because he/she must be able to manage and report on the QMS. It depends on the size of the factory but for small organizations (less than 20 people), the QMS manager can have another function in the organization, like human resources or financial manager. The QMS is a full LQMS and does not require a long period of availability in order to be managed. Actually, this model is Lean in all its forms because it does not need a specific resource to manage it. Indeed, the system is "Lean" even at the management level: it no longer requires an assigned manager; the manager of another department can control the QMS (i.e. Human Resources Manager). In very small firms, it is even possible to outsource the QMS function to an external expert, one or two days per month.

\section{An application in a company}

The proposed methodology of "Lean Normalization" for QMS (LQMS) was applied in the company PBCA, which is a one-person independent business, created in 2005. The current staff of the company is composed of one permanent manager (Freelancer) but involves a network of ten freelance consultants. This French firm specializes in QSE consulting/training and methods in Lean Management for all types of businesses (from small and medium sized companies to multinational groups). The principal motivation of PBCA was to self-apply the solutions it recommended to its customers in order to generate more credibility for the LQMS approach.

To assess the reproducibility of the ongoing research studies, an independent group of four students completing a Bachelor's Degree in Quality Management rigorously conducted the implementation of the LQMS. These students were trained in the application of this methodology during their university studies.

Based on the six-step model, the implementation process of the LQMS is described using the following ten deadlines:

- A01 - Documentary Muda:

(1) Implementation of the draft manual with an organizational chart, job descriptions and process mapping (in SIPOC form), identification of measurement tools.

(2) Implementation of procedures for documentary management and audit management.

(3) Implementation of the procedure for corrective and preventive actions as well as for nonconformities, and customer satisfaction surveys.

- A02 - Right Documents:

(4) Establishment of organized Records Management Standards (nineteen) developed jointly with the Senior Management.

- A03 - Design of the Continuous Improvement Process:

(5) Kickoff of the implementation of quality assurance by all members of staff, carrying out the first quality diagnostic.

(6) Implementation of the QMS steering committees: Steering committee of the processes and management review, first record of these two authorities. 
(7) Implementation of the files for permanent improvement and quality monitoring.

- A04 - Due Quality:

(8) First internal audit.

(9) Second management review, updated by the records and the files of the QMS.

- A05 - Visual Communication (establishment of the scorecard and steering indicators).

- A06 - QMS Animation:

(10) End of non-conformity audit.

In the first step, the Quality Manual is limited to a single page and includes the SIPOC form (Figure 6). Then, the procedure of documentation management (including records) and progress management (including non-conformity and action) are included in the same document (Figure 14).

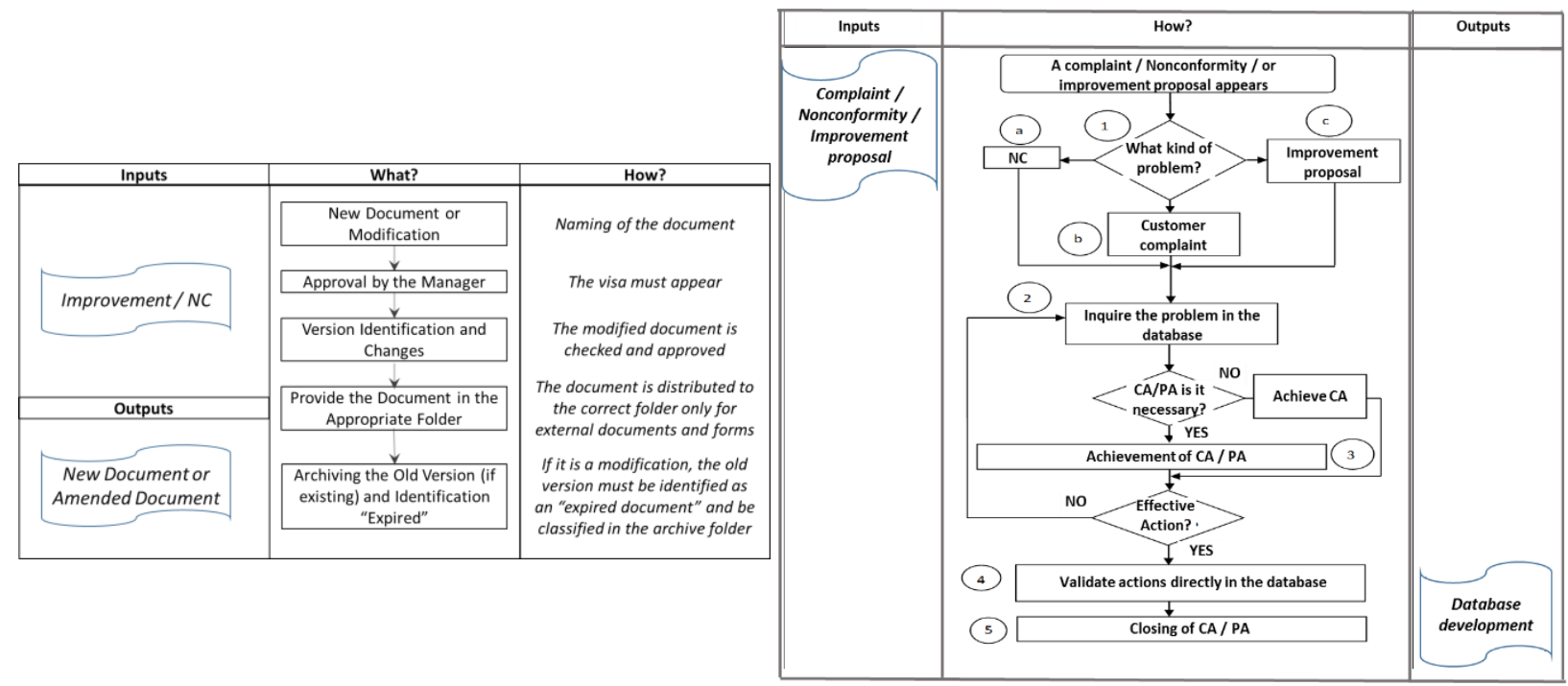

Figure 14. The quality procedure in a single page

For the second step, only ten records are effective for this Lean QMS:

- Continuous data base,

- Customer satisfaction survey,

- Perusal of the satisfaction survey,

- Invoices,

- Quality forecast,

- Internal audit report,

- Management review,

- Scorecard,

- Quality Manual,

- Documentary listing.

All the subsequent steps enable the improvement of the LQMS and the measurable results are:

- Total satisfaction of all the customers,

- No complaints from customers for two years,

- No major non-conformity during the internal audit and the certification audit. 
In July 2015, the firm PBCA was certified by AB certification with an LQMS documentation system that was twenty pages long and contained a fully documented continuous improvement process.

In order to achieve the required goal of ISO 9001 certification, the implementation process delay was only ten working days (approximately at a cost of 10,000 dollars). One of the biggest advantages was that the implementation cost for PBCA was typically lower than usual because the students carrying out the project were not paid so that specific spending only included the certification audit fees (approximately 2,000 dollars). In the case of traditional certification programs, the cost of the certification would have been greater (approximately five times) because the relevant completion timeframe would have been longer (usually, it requires about 40 to 50 business days).

A twenty-page document describes the LQMS (one quality manual, six procedures and about twenty records) while a traditional implementation would have needed a much bigger, more detailed document. The LQMS does not require any improvement and is able to be managed with no specifically attributed human resource.

Since obtaining this certification, PBCA has noticed an increase of $20 \%$ in business and the customer satisfaction survey indicates a regular increase of $5 \%$ in customer satisfaction every year. Therefore, from the outcome of this investigation it is possible to conclude that the results of this research are quite convincing.

\section{Conclusion}

Following a thorough literature review of the concepts of Lean Management and the ISO standard, certain important concepts of Lean manufacturing (such as just-in-time, elimination of waste, continuous improvement, perfect quality, visual management, and human resources management) were merged with the ISO 9001 standard in a structured and organized methodology.

The so-called "Lean Normalization" of a Quality Management System (LQMS) thus allows a standard to be implemented quickly, in an effective way and, with just the right level of documentation. This methodology is entirely compatible with ISO standards or ISO/TS 16949 (an ISO 9001-based technical specification published in June 1999 aiming at the development of a QMS in the automotive industry) or AS standards (AS 9100 is a widely adopted and standardized QMS for the aerospace industry).

Furthermore, the new versions of the ISO standards (ISO 9001 and ISO 14001), released in September 2015, are also compatible with this proposal. It is designed to avoid classifying too many documents in processes, procedures and records, but also in the new concept entitled "documented information" defined as the meaningful data that is required to be controlled and maintained by the organization. Any standard can thus benefit from this research work in order to reduce drastically the quantity of right documents.

Therefore, this paper is a contribution to the ongoing research on combining Lean and ISO 9001based Quality Management System:

- by proposing a methodology that aims to bridge the existing gap in the literature concerning the interrelationship between Lean philosophy and a management standard such as ISO 9001,

- by applying this methodology using the most common tools of Lean Management to various companies.

This methodology has been already applied to about ten known companies, not foreseen in this research project (ATD Group, Dalkia Group, Coupery \& Masson, ACCEL, M2OCity, ERVOR, 
IUT Cergy-Pontoise, etc.) that have benefited from the results of this specific research studies. All these firms have successfully achieved ISO 9001 certification in a very short time by respecting a ten-deadline implementation. Ten consulting days were sufficient to achieve successfully an initial certification audit whereas usually consulting firms propose a support towards certification of several months.

Definitely, as beneficial results were obtained when applying in companies, it is expected that this work could be very useful to operating managers because the objective of this methodology is to simplify and limit the documents without jeopardizing the achievement of certification.

The advantage of this methodology, besides its rapid implementation is that the impacts on the processes of the company are "visible" (performance indicators reach the expected goals). Indeed, all the companies that have used this methodology have produced significant benefits growth (the net sale increases) and have noticed an increase in customer satisfaction.

\section{References}

Åhlström, P. (1998), "Sequences in the Implementation of Lean Production", European Management Journal, Vol. 16 No. 3, pp. 327-334.

Ahmad, M., Zakuan, N., Jusoh, A. and Takala, J. (2012), "Relationship of TQM and Business Performance with Mediators of SPC, Lean Production and TPM", Procedia-Social and Behavioral Sciences, Vol. 65, No. 3, pp. 186-191.

Al-Tahat, M. D. and Jalham, I. S. (2015), "A structural equation model and a statistical investigation of lean-based quality and productivity improvement", Journal of Intelligent Manufacturing, Vol. 26, No. 3, pp. 571-583.

Atmaca, E. and Girenes, S. S. (2013), "Lean Six Sigma methodology and application", Quality and Quantity, Vol. 47, No. 4, pp. 2107-2127.

Bacoup, P., Habchi, G. and Pralus, M. (2014), "Mise en synergie de l'approche Lean Management et du système de management documentaire de l'ISO 9001", paper presented at the International Conference on Modeling, Optimization and Simulation (MOSIM), 5-7 November, Nancy, France.

Bacoup, P., Michel, C., Habchi, G. and Pralus, M. (2015a), "Implementation of ISO and Lean Management into administration - Application in a University Department", paper presented at the 11 ème Congrès International Pluridisciplinaire en Qualité, Sureté de fonctionnement et Développement Durable (QUALITA'2015), 17-19 March, Nancy, France.

Bacoup, P., Michel, C., Habchi, G. and Pralus, M. (2015b), "Lean Normalization and Organisational Stress test: a new approach for Quality Management System", paper presented at the $11^{\text {ème }}$ Congrès International de Génie Industriel (CIGI 2015), 26-28 October, Québec, Canada.

Bakri, A., Abdul Rahim, A. R., Yusof, N. M. and Ahmad, R. (2012), "Boosting Lean Production via TPM", Procedia - Social and Behavioral Sciences, Vol. 65, pp. 485-491.

Ballé, M. and Beauvallet, G. (2013), Le management lean, Pearson, Paris.

Behrouzi, F. and Wong, K. Y. (2011), "Lean performance evaluation of manufacturing systems: a dynamic and innovative approach", Procedia Computer Science, Vol. 3, No. 1, pp. 388-395.

Blecken, A., Zobel, A. and Maurantzas, E. (2011), "Development of a Lean Quality Management System: An Integrated Management System", Lecture Notes in Business Information Processing, Vol. 46, pp. 141-151.

Bortolotti, T., Boscari, S. and Danese, P. (2015), "Successful lean implementation: Organizational culture and soft lean practices", International Journal of Production Economics, Vol. 160, pp. 182-201.

Chavez, R., Yu, W., Jacobs, M., Fynes, B., Wiengarten, F. and Lecuna, A. (2015), "Internal lean practices and performance: The role of technological turbulence", International Journal of Production Economics, Vol. 160, pp. 157-171.

Chiarini, A. (2011), "Integrating lean thinking into ISO 9001: a first guideline", International Journal of Lean Six Sigma, Vol. 2 No. 2, pp. 96-117.

Cuatrecasas-Arbos, L., Fortuny-Santos, J. and Vintro-Sanchez, C. (2011), "The Operations-Time Chart: A graphical tool to evaluate the performance of production systems - From batch-and-queue to lean manufacturing", Computers and Industrial Engineering, Vol. 61 No. 3, pp. 663-675. 
Deif, A. (2012), "Assessing Lean Systems Using Variability Mapping", in Chryssolouris, G. and Mourtzis, D. (Ed.), Procedia 45th CIRP Conference on Manufacturing Systems, Elsevier, Vol.3, pp. 2-7, Athens.

Din, S., Abd-Hamid, Z. and Bryde, D.J. (2011), "ISO 9000 certification and construction project performance: The Malaysian experience", International Journal of Project Management, Vol. 29 No. 8, pp. 1044-1056.

Dombrowski, U., Mielke, T. and Engel, C. (2012), "Knowledge Management in Lean Production System", in Chryssolouris, G. and Mourtzis, D. (Ed.), Procedia 45th CIRP Conference on Manufacturing Systems, Elsevier, Vol.3, pp. 436-441, Athens.

Dominici, G., and Palumbo, F. (2012), "Decoding the Japanese Lean Production System According to a Viable Systems Perspective", Systemic Practice and Action Research, Vol. 26 No. 2, pp. 153-171.

Eroglu, C. and Hofer, C. (2011), "Lean, leaner, too lean? The inventory-performance link revisited", Journal of Operations Management, Vol. 29, No. 4, pp. 356-369.

Fagerlind Stahl, A., Gustavsson, M., Karlsson, N., Johansson, G. and Ekberg, K. (2015), "Lean Production Tools and decision latitude enable conditions for innovative learning in organizations: a multilevel analysis", Applied Ergonomics, Vol. 47, pp. 285-291.

FDX 50-819 (2011), "Lignes directrices pour mettre en synergie le lean management et l'ISO 9001", AFNOR, Saint Denis.

Fullerton, R. R., Kennedy, F. A. and Widener, S. K. (2013), "Management accounting and control practices in a lean manufacturing environment", Accounting, Organizations and Society, Vol. 38 No. 1, pp. 50-71.

Gligor, D. M., Esmark, C. L. and Holcomb, M. C. (2015), "Performance outcomes of supply chain agility: when should you be agile?", Journal of Operations Management, Vol. 33, pp. 71-82.

Gnogni, M., Andriulo, S., Maggio, G. and Nardone, P. (2013), "'Lean Occupational" safety: An application for a Near-miss Management System design", Safety Science, Vol. 53, pp. 96-104.

Hofer, C., Eroglu, C. and Hofer, A. R. (2012), "The effect of lean production on financial performance: the mediating role of inventory leanness", International Journal of Production Economics, Vol. 138 No. 2, pp. 242-253.

Holtskog, H. (2013), "Continuous Improvement beyond the Lean understanding", in Cunha, P.F. (Ed.), Procedia $46^{\text {th }}$ CIRP Conference on Manufacturing Systems, Elsevier, Vol. 7, pp. 575-579, Sesimbra.

Holweg, M. (2007), "The Genealogy of Lean Production", Journal of Operations Management, Vol. 25 No.2, pp. 420-437.

IDEF0 (1993) "Announcing the Standard for Integration Definition for Function Modeling (IDEF0)", National Institute of Standards and Technology, Ohio.

Imai, M. (1997). Gemba Kaizen: a commonsense, low-cost approach to management, McGraw-Hill, New York.

Jabbour, C. J., De Susa Jabbour, A., Govindan, K., Texeira, A. A. and De Suza Freitas, W. R. (2013), "Environmental management and operational performance in automotive companies in Brazil: The role of human resource management and lean manufacturing", Journal of Cleaner Production, Vol. 47, pp. 129-140.

James-Moore, S. and Gibbons, A. (1997), "Is Lean manufacture universally relevant? An investigative methodology", International Journal of Operations \& Production Management, Vol. 17 No.9, pp. 899-911.

Johnstone, C., Pairaudeau, G. and Pettersson, J. A. (2011), "Creativity, innovation and lean sigma: a controversial combination?", Drug Discovery Today, Vol. 16 No. 1/2, pp. 50-57.

Krogstie, L. and Martinsen, K. (2013), "Beyond Lean and Six Sigma; Cross-Collaborative Improvement of Tolerances and Process Variations - A Case Study", in Cunha, P.F. (Ed.), Procedia $46^{\text {th }}$ CIRP Conference on Manufacturing Systems, Elsevier, Vol. 7, pp. 610-615, Sesimbra.

Liker, J. K. (2004), The Toyota Way: 14 Management Principles from the World's Greatest Manufacturer. McGraw-Hill, New York.

Lyonnet, B., (2010). Amélioration de la performance industrielle : vers un système de production Lean adapté aux entreprises du pôle de compétitivité Arve Industries Haute-Savoie Mont-Blanc, $\mathrm{PhD}$ Thesis, Université de Savoie, Annecy, France. 
Lyonnet, B., Pillet, M. and Pralus M. (2010), "Lean Manufacturing in the screw cutting sector: assessment of maturity level", International Journal of Rapid Manufacturing, Special Issue on Lean Manufacturing, Vol. 1 No 3, pp. 256-277.

Marca, D. A. and McGowan, C. L. (1988), SADT: structured analysis and design technique, McGraw-Hill, New York, NY.

McGuire, S. J. and Dilts, D. M. (2008), "The financial impact of standard stringency: An event study of successive generations of the ISO 9000 standard", International Journal of Production Economics, Vol. 113 No. 1, pp. 3-22.

Metternich, J., Bollhoff, J., Seifermann, S. and Beck, S. (2013), "Volume and Mix Flexibility Evaluation of Lean Production Systems", in Makris, S. (Ed.), Procedia $2^{\text {nd }}$ CIRP Global Web Conference Beyond modern manufacturing: Technology for the factories of the future, Elsevier, Vol. 9, pp. 7984.

Micklewright, M. (2010), Lean ISO 9001: Adding spark to your ISO 9001 QMS and Sustainability to Your Lean Efforts, ASQ Quality Press, Milwaukee.

Nasab, H. H., Bioki, T. A., and Zare, H. K. (2012), "Finding a probabilistic approach to analyze lean manufacturing", Journal of Cleaner Production, Vol. 29-30, pp. 73-81.

Naveh, E. and Marcus, A. (2005), "Achieving competitive advantage through implementing a replicable management standard: Installing and using ISO 9000", Journal of Operations Management, Vol. 24 No. 1, pp. 1-26.

Netland, T. H., Schloetzer, J. D. and Ferdows, K. (2015), "Implementing corporate lean programs: the effect of management control practice", Journal of Operations Management, Vol. 36, pp. 90-102.

Ohno, T. (1988), Toyota Production System: Beyond Large-Scale Production. Productivity Press, Portland.

Pamfilie, R., Petcu, A. J. and Draghici, M. (2012), "The importance of Leadership in Driving a Strategic Lean Six Sigma Management", in Özşahin, M. and Zehir, C (Ed.), $8^{\text {th }}$ International Strategic Management Conference, Procedia - Social and Behavioral Sciences, Elsevier, Vol. 58 No. 12, pp. 187-196, Barcelona.

Peter, K. and Lanza, G. (2011), "Company-specific quantitative evaluation of lean production methods", Production Engineering Research and Development, Vol. 5 No. 1, pp. 81-87.

Piatyszek, E. and Karagiannis, G. M. (2012), "A Model-Based Approach for a Systematic Risk Analysis of Local Flood Emergency Operation Plans: A First Step toward a Decision Support System", Natural Hazards, Vol. 61 No 3, pp. 1443-1462.

Priede, J. (2012), "Implementation of Quality Management System ISO 9001 in the World and its Strategic Necessity", in Özşahin, M. and Zehir, C (Ed.), 8th International Strategic Management Conference, Procedia - Social and Behavioral Sciences, Elsevier, Vol. 58 No. 12, pp. 1466-1475, Barcelona.

Purvis, L., Gosling, J. and Naim, M. M. (2014), "The development of a lean, agile and leagile supply network taxonomy based on differing types of flexibility", International Journal of Production Economics, Vol. 151, pp. 100-111.

Rahani, A. and Al-Ashraf, M. (2012), "Production Flow Analysis through Value Stream Mapping: A Lean Manufacturing Process Case Study", in Makhtar, A.K., Yussof, H., Al-Assadi, H. and Low C. Y. (Ed.), International Symposium on Robotics and Intelligent Sensors, Procedia Engineering, Elsevier, Vol. 41, pp. 1727-1734, Sarawak, Malaysia.

Ravet, D. (2011), "Lean production and agile organization: the link between supply chain and sustainable development", working paper, Magellan Research Center, 2011, Lyon.

Schwarz, P., Pannes, K. D., Nathan, M., Reimer, H. J., Kleespies, A., Kuhn, N., Rupp, A. andZügel, N. P. (2011), "Lean processes for optimizing OR capacity utilization: prospective analysis before and after implementation of value stream mapping (VSM)", Langenbeck's Archives of Surgery, Vol. 396 No. 7, pp. 1047-1053.

Shah, R. and Ward, P. T. (2007) "Defining and developing measure of lean production", Journal of Operations Management, Vol. 25 No. 4, pp. 785-805.

Sharma, D. (2005), "The association between ISO 9000 and financial performance", The International Journal of Accounting, Vol. 40 No. 2, pp. 151-172.

Stålhane, T. (2006), "Implementing an ISO 9001 Certified Process", in Richardson, I., Runeson, P. and Messnarz, R. (Eds.), EuroSPI 2006, LNCS 4257, Springer-Verlag Berlin, pp. 16-27.

Tamayo-Torres, J., Gutierrez-Gutierrez, L. and Ruiz-Moreno, A. (2014), "The relationship between exploration and exploitation strategies, manufacturing flexibility and organizational learning: An 
empirical comparison between Non-ISO and ISO certified firms", European Journal of Operational Research, Vol. 232 No. 1, pp. 72-86.

Terlaak, A. and King, A. A. (2006), "The effect of certification with the ISO 9000 Quality Management Standard: A signaling approach", Journal of Economic Behavior \& Organization, Vol. 60 No. 4, pp. 579-602.

Terziovski, M., Power, D. and Sohal, A. S. (2003), "The longitudinal effects of the ISO 9000 certification process on business performance". European Journal of Operational Research, Vol. 146, No. 3, pp. $580-595$.

Turk, A. M. (2006), "ISO 9000 in construction: An examination of its application in Turkey", Building and environment, Vol. 41, No. 4, pp. 501-511.

Turner, R. and Lane, J. A. (2013), "Goal-Question-Kanban: applying lean concepts to coordinate multilevel systems engineering in large enterprises", in Paredis, C.J.J., Bishop, C. and Bodner, D. (Ed.), Conference on Systems Engineering Research, Procedia Computer Science, Elsevier, Vol. 16, pp. 512-521, Atlanta.

Tyagi, S., Cai, A., Yang, K. and Chambers, T. (2015), "Lean tools and methods to support efficient knowledge creation", International Journal of Information Management, Vol. 35 No. 2, pp. 204-214.

Waldner, J.-B. (1992), CIM: Principles of Computer Integrated Manufacturing, John Wiley \& Sons, Chichester.

Wasim, A., Shehab, E., Abdalla, H., Al-Ashaab, A., Sulowski, R. and Alam, R. (2013), "An innovative cost modelling system to support lean product and process development", International Journal of Advanced Manufacturing Technology, Vol. 65 No 1/4, pp. 165-181.

Wilson, H. M. (1998), "Do the right things right?", Quality Progress, Vol. 31 No. 12, pp. 27-30.

Withers, B. and Ebrahimpour, M. (2000), "Does ISO 9000 Certification Affect the Dimensions of Quality Used for Competitive Advantage?", European Management Journal, Vol. 18 No. 4, pp. 431-443.

Womack, P.J. and Jones, T.J. (1996), Lean Thinking: Banish Waste and Create Wealth in Your Corporation, Simon \& Schuster, New York, NY.

Yang, M., Hong, P. and Modi, S. (2011), "Impact of lean manufacturing and environmental management of business performance: an empirical study of manufacturing firms", International Journal of Production Economics, Vol. 129 No. 2, pp. 251-261.

Yuan-Han H. and Anand K. G. (2014). Systematic Engineering Tools for Describing and Improving Medication Administration Processes at Rural Healthcare Facilities. Applied Ergonomics, Vol. 45 No. 6, pp. 1712-1724. http://dx.doi.org/10.1016/j.apergo.2014.06.003

Article ref:

The TQM Journal, Vol. 30 No. 1, 2018, pp. 1-25, @ Emerald Publishing Limited, 1754-2731, DOI 10.1108/TQM-06-2016-0053 